\title{
CIBERPERIODISMO EN EVOLUCIÓN
}

Ocampo-Villegas, María. Universidad de La Sabana (Colombia)

maria.ocampo@unisabana.edu.co

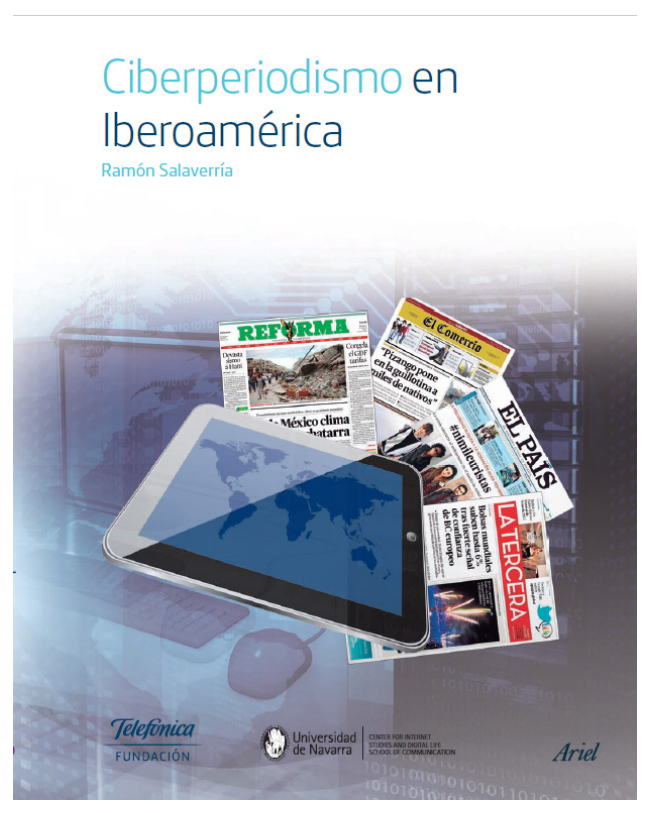

Cada cierto tiempo surgen obras con las características necesarias para convertirse en referentes de un campo de estudio. Esta es una de ellas. Con la coordinación del profesor Ramón Salaverría, de la Universidad de Navarra, treinta académicos de veintidós países se dieron a la tarea de recopilar la historia del surgimiento y de la evolución del ciberperiodismo en Iberoamérica.

Este documento aporta detalles poco explorados que permiten observar el contexto tecnológico en el que empezaron a emerger los primeros medios digitales, los perfiles de los periodistas, el marco legal y las perspectivas de desarrollo del periodismo digital en Argentina, Bolivia, Brasil, Chile, Colombia, Costa Rica, Cuba, Ecuador, El Salvador, España, Guatemala, Honduras, México, Nicaragua, Panamá, Paraguay, Perú, Portugal, Puerto Rico, República Dominicana, Uruguay y Venezuela.

Gracias a la estructura con la que fueron planeados los capítulos, que abordan iguales elementos para cada país, para los investigadores interesados en este campo de estudio, será posible hacer un abordaje comparativo sobre las características iniciales y actuales del periodismo digital iberoamericano. De allí su importancia, ya que a partir de esta obra, se esperarían nuevos estudios que den cuenta de las posibilidades de desarrollo y evolución del ciberperiodismo en la región o en cada país.

Entre 1994 y 1996, aparecieron los primeros medios digitales, que en ese entonces eran tan solo el volcado a la web de los mismos contenidos de las versiones impresas de los periódicos, pioneros en cada país en dar el salto al ámbito digital. Por aquella época, solo treinta millones de personas tenían acceso a Internet en el mundo entero y, habrá que decirlo, muy pocas de ellas estaban en América Latina. Sin embargo, los medios fueron capaces de visualizar el futuro y poco a poco se fueron adecuando a las posibilidades que las tecnologías, entonces "nuevas", daban para generar contenidos y difundirlos con una inmediatez nunca antes vista. Hoy, veinte años después, los usuarios de Internet son cerca de 3.000 millones de personas.

Con todo, como bien lo dice en el prólogo el profesor Rosental Alves, veinte años después "el ciberperiodismo todavía parece más un adolescente en los años de formación de su personalidad que un adulto que sabe lo que 
quiere y hacia dónde desea ir" (p. XII). El camino por andar es todavía incierto para los medios de comunicación, que aún no han podido desprenderse del todo del lastre de un modelo de negocio que solía ser bastante productivo, pero ha entrado en decadencia y no ha encontrado muy bien la manera de reinventarse.

A primera vista, la comparación de la evolución de los medios digitales iberoamericanos da cuenta de que cada uno ha tomado un camino propio, con estrategias para posicionarse como líderes de su propio país, pero pasan por alto la posibilidad de traspasar las fronteras y de aprovechar que la red hace posible pensar en alianzas e impactos transnacionales.

Como señala el profesor Salaverría en el contexto general de esta obra:

[...] solo desde los últimos años ha comenzado a arraigar una estrategia decididamente iberoamericana en algunos medios digitales. Webs como las de El País (www.elpais.com), El Mundo (www.elmundo.es) y el diario deportivo Marca (www.marca.com) desde España, o teleSUR (www.telesurtv.net) desde Venezuela, han decidido dejar de ser simples medios nacionales y han optado, en cambio, por ampliar su público objetivo a toda Iberoamérica (p. XXI).

Quizás allí esté el futuro. Está por verse.

Otro de los aportes importantes de esta obra, editada por Fundación Telefónica y Ariel, se encuentran en las cifras comparativas que se publican en el contexto general. Allí se encuentran, por ejemplo, la clasificación de desarrollo de las tecnologías de la información en Iberoamérica, realizado con base en la información de la Unión Internacional de Telecomunicaciones de 2014 o las cifras del porcentaje de usuarios de Internet de cada uno de los veintidós países, entre 2000 y 2013, datos valiosísimos para los investigadores del periodismo digital y del desarrollo de las telecomunicaciones.

Valga enumerar solo estas bondades de la obra, de gran envergadura, que seguramente se convertirá en un libro obligado de consulta para investigadores de la comunicación y del periodismo.

\section{Datos del libro}

Autor: Ramón Salaverría (coordinador)

Fecha: 2015

Título completo: Ciberperiodismo en Iberoamérica

Ciudad: Madrid

Editorial: Fundación Telefónica y Ariel

Páginas: 441 